Archived version from NCDOCKS Institutional Repository http://libres.uncg.edu/ir/asu/

\title{
Appalachľan
}

B O O N E, N O R T H C A R O L I N A

\section{U.S. Long-Haul Truck Driver Work Organization And The Association With Cardiometabolic Disease Risk}

\author{
By: Adam Hege, Michael Kenneth Lemke, Yorghos Apostolopoulos, \\ Mike Perko, Sevil Sonmez, \& Robert Strack
}

\begin{abstract}
Work organization, including long working hours, irregular work schedules, and job stress, has been associated with increased cardiometabolic disease (CMD) risk for numerous working populations. The purpose of this study was to examine the associations between work hours, work schedules, job stress, and CMD risk for a sample of US long-haul truck drivers (LHTDs). A nonexperimental, descriptive, cross-sectional design was employed to collect survey and anthropometric data from 260 US LHTDs at a major truck stop. The mean BMI was $33.40 \mathrm{~kg} / \mathrm{m}^{2}$ and mean waist circumference was $114.77 \mathrm{~cm}$. Using logistic regression, researchers found longer work hours, especially greater than 11 hours daily, were associated with increased odds for an extremely high risk of CMD. Results support comprehensive and integrated approaches that address work organization, and in particular long working hours, to reduce drivers' CMD risk.
\end{abstract}

Hege A, Lemke MK, Apostolopoulos Y, Perko M, Sönmez S, Strack R. US long-haul truck driver work organization and the association with cardiometabolic disease risk. Archives of Environmental \& Occupational Health. 2017;72(5):303-310. doi:10.1080/19338244.2016.1242468. Publisher version of record available at: https://www.tandfonline.com/doi/full/10.1080/19338244.2016.1242468 


\title{
US long-haul truck driver work organization and the association with cardiometabolic disease risk
}

\author{
Adam Hege $^{a}$, Michael Kenneth Lemke ${ }^{b, c}$, Yorghos Apostolopoulos ${ }^{b, c}$, Mike Perko $^{d}$, Sevil Sönmez ${ }^{e}$, \\ and Robert Strack ${ }^{\mathrm{d}}$ \\ ${ }^{a}$ Holmes Convocation Center, Department of Health and Exercise Science, Appalachian State University, Boone, North Carolina, USA; \\ ${ }^{\mathrm{b} C}$ Complexity and Computational Population Health Group, Texas A\&M University, College Station, Texas, USA; 'Department of Health and

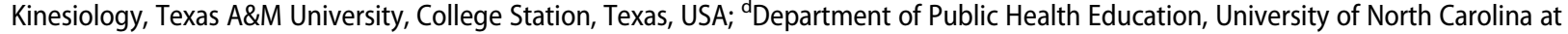 \\ Greensboro, Greensboro, North Carolina, USA; ${ }^{\mathrm{e}}$ Department of Tourism and Attractions, University of Central Florida, Orlando, Florida, USA
}

\begin{abstract}
Work organization, including long working hours, irregular work schedules, and job stress, has been associated with increased cardiometabolic disease (CMD) risk for numerous working populations. The purpose of this study was to examine the associations between work hours, work schedules, job stress, and CMD risk for a sample of US long-haul truck drivers (LHTDs). A nonexperimental, descriptive, cross-sectional design was employed to collect survey and anthropometric data from 260 US LHTDs at a major truck stop. The mean BMI was $33.40 \mathrm{~kg} / \mathrm{m}^{2}$ and mean waist circumference was $114.77 \mathrm{~cm}$. Using logistic regression, researchers found longer work hours, especially greater than 11 hours daily, were associated with increased odds for an extremely high risk of CMD. Results support comprehensive and integrated approaches that address work organization, and in particular long working hours, to reduce drivers' CMD risk.
\end{abstract}

\section{KEYWORDS}

Cardiometabolic disease (CMD); LHTD; obesity; work organization
Over the past several decades, globalization of markets, technological advances, deregulation of industries, and declines in union membership have profoundly changed the organization of work in the United States, contributing to occupational health disparities. ${ }^{1}$ Changes to the organization of work include longer work hours, irregular work schedules, and increased job stress. ${ }^{1}$ Currently, among all industrialized nations, the United States has the longest average working hours on a yearly basis, and the proportion of workers working long hours has increased substantially over the past 3 decades. ${ }^{2,3}$ Shift work, referring to any work shift outside the 7 AM to 6 PM period or rotating daily/nighttime shifts, is commonplace among US workers. ${ }^{3}$ In $2010,28.7 \%$ of workers reported working alternative or rotating shifts, up from $17.7 \%$ in $2004 .{ }^{4}$ These patterns of work organization induce job stress, which is exacerbated by key psychological demands frequently experienced by US workers including fast work pace, time pressures, having to learn new things, repetitive work, and low social support from coworkers and supervisors. ${ }^{5,6}$

These features of work organization have become pervasive across most US labor sectors, which includes long-haul truck drivers (LHTD). The work organization of US LHTD, of which there are approximately 1.7 million, is characterized by long work hours and irregular work schedules. ${ }^{7}$ These work organization characteristics, in turn, induce and exacerbate job stress. ${ }^{7,8}$ Work organization of long-haul truck drivers is heavily influenced by federal and corporate policy; namely, the Department of Transportation's (DOT's) hours of service (HOS) regulations, which are designed to regulate drivers' driving activities, and trucking companies' operations, which are designed to maximize profit and productivity, largely in response to the trucking industry's increasingly hypercompetitive nature since deregulation in the 1980 s. $^{7}$ As a result, drivers experience time pressures due to tight-running and erratic delivery schedules and little control over the conditions influencing their work. ${ }^{7}$ Another consequence of deregulation was a decline in drivers' wages, working conditions, and bargaining power, as the influence of unions declined. ${ }^{8}$ Because truck drivers are exempt from the Fair Labor Standards $\mathrm{Act}^{8}{ }^{8}$ they are underpaid and frequently perform work for which they are not compensated. In response, drivers work longer to maintain their livelihood, and in the process frequently violate HOS rules by abbreviating mandated rest periods and extending 
working and driving hours beyond the mandated legal limit ${ }^{9}$-behaviors that further exacerbate detrimental aspects of work organization and further induce cardiometabolic disease (CMD) risk. This work environment has been described as "obesogenic" and influences multiple deleterious health outcomes, with US LHTD having higher morbidity rates and more frequent workplace accidents and injuries compared to the general US population. $^{9-12}$

Work organizations characterized by long work hours, irregular work schedules, and high job stress are associated with increases in obesity-related CMD risk factors. General obesity, or body mass index (BMI) of greater than $30 \mathrm{~kg} / \mathrm{m}^{2}$, has been linked to these work organization features. ${ }^{13}$ General obesity is highly prevalent among US LHTD, with a recent national survey finding that nearly $70 \%$ are obese-more than double the rate of all US workers. ${ }^{14}$ Obesity increases risks for CMD, including hypertension, diabetes, metabolic syndrome, and cardiovascular disease. ${ }^{14}$ It is not surprising that US LHTD have a higher prevalence of hypertension (26\% vs $24 \%)$ and diabetes $(14 \%$ vs $7 \%)$ compared to other US workers. ${ }^{14}$ Abdominal or centralized obesity, defined as waist circumference (WC) of greater than 102 centimeters, is associated with CMD outcomes such as hypertension, diabetes, metabolic syndrome, and cardiovascular disease; further, the combination of increased BMI and waist circumference intensifies risk for these outcomes. ${ }^{15-17}$

With uncertainty regarding the influence of work organization on obesity and CMD risk among US LHTD — and the numerous associated consequences for safety and health-the work organization of US LHTD deserves further attention. ${ }^{7,18}$ Specifically, it is critical to understand how work organization exacerbates the already obesogenic environment of long-haul trucking in the United States to generate excessive CMD risk. ${ }^{10,12,19}$ Further, with obesity and CMD risk being associated with multiple body composition measures, exploration of how the work environment potentially influences both general obesity (BMI) and abdominal obesity (WC) is warranted. As such, the purpose of this study is to examine the relationships between the work organization factors of work hours, work schedules, and job stress and CMD risk for US LHTD.

\section{Methods}

\section{Study design and participants}

The study was approved by the Institutional Review Board (IRB) of The University of North Carolina at Greensboro. A nonexperimental, descriptive, crosssectional design was employed to collect survey, anthropometric, and biometric data from 260 US LHTD over 6 months at a truck stop located in North Carolina. Because the truck stop is private property, permission to conduct the study at the truck stop was requested and granted by the truck stop's corporate office.

Researchers spent approximately 3 days each week at the truck stop in teams, with one team of two researchers remaining at the truck stop from approximately $6 \mathrm{PM}$ to 10 PM; the 6-10 PM period was utilized given that in consultation with truck stop management, it was concluded that it was the peak time for drivers ending their daily driving time and entering the truck stop at the conclusion of their workday. Signs regarding the study were posted at strategic locations around the truck stop. The truck stop was chosen for its relatively high volume due to it being along a major US interstate (Interstate 40), its lack of barriers to potential driver clientele (eg, they are open to the public, and drivers are not charged for parking there), and its size allowing numerous LHTDs to park their trucks, spend the night, eat meals, shower/ bathe, and spend their free time. Using intercept techniques, researchers approached drivers inside the truck stop, asking screening questions to assure they were US LHTDs and that they had an overnight layover at the truck stop. Drivers were approached in multiple locations inside the truck stop, including in the dining areas, convenience store, game room/arcade area, and TV and entertainment area. For this study, LHTDs were considered those that are on the road away from home for extended amounts of time and travel all over the United States. During this conversation, study details, including the voluntary nature of participation and cash incentives, were described. Enrolled drivers were then asked to sign an informed consent form and were allowed to use aliases for greater confidentiality and in some cases anonymity. LHTD participants were first administered the survey in a face-to-face and paper-based interview format, followed by collection of anthropometric measures (height, weight, etc.), and drivers were paid a $\$ 10$ cash incentive. With Type I error set at .05 and power at $90 \%$, our sample size was anticipated to enable us to conduct appropriate statistical analyses, including examining significant differences among independent and outcome variables.

\section{Survey data}

We developed the Trucker Sleep Disorders Survey (TSLDS) from insights gleaned from other key instruments, relevant sleep literature, and our previous work with truck drivers. $^{20,21}$ The TSLDS was organized into 5 sections, which assessed (1) trucking work environment, (2) individual work- and health-related factors, (3) self-reported sleep 
disturbances and sleep disorders, (4) self-reported health consequences, and (5) self-reported comorbidities. Key independent variables for this study included those related to work hours, work schedules, and job stress.

\section{Work hours}

Work hours were measured by asking drivers, "How many hours of work do you average on a daily basis including both driving and other duties?" Response selections included "less than 6 hours," "between 6 and 7 hours," "between 7 and 8 hours," "between 8 and 9 hours," "between 9 and 10 hours," "10-11 hours," "1112 hours," "12-13 hours," "13-14 hours," and "over 14 hours." On the basis of government regulations, which stipulate a maximum of 11 hours of driving time without taking a 10-hour break, ${ }^{22}$ and the high number of hours worked by drivers in our sample (only three of the 260 drivers in our sample worked $8 t$ or fewer hours per day), the number of hours worked was categorized for analysis as "11 hours or less," or "more than 11 hours."

\section{Work schedules}

To measure participants' experiences with rotating work schedules, the following question was asked: "Is your daily work schedule the same each day?" The response selections were "same" or "different." Drivers were then asked about their perception of delivery schedules. Supervisors, more commonly referred to as dispatchers, schedule delivery times and monitor drivers' driving time. Specifically, the following question was asked: "How often do you consider your delivery schedule to be realistic?" The response selections included "never," "rarely," "sometimes," "frequently," and "always." For analysis, "never," "rarely," and "sometimes" responses were categorized as "unrealistic"; "frequently" and "always" responses were categorized as "realistic."

\section{Job stress}

Seven questions were asked regarding job stress, which assessed frequency of fast work pace, time pressures, repetitive work, learning new things, coworker support, and supervisor support. For 6 of the 7 questions, the response selections were "never," "rarely," "sometimes," "frequently," and "always." For analysis, "never," "rarely," and "sometimes" responses were categorized as "low"; "frequently" and "always" responses were categorized as "high." For the seventh question that asked drivers about their perceived job stress, specifically how they would characterize or describe their job stress level, response selections included "no stress," "mild stress," "moderate stress," "high stress," "very high stress," and "chronic stress." For analysis, "no stress" and "mild stress" responses were categorized as "low stress"; "moderate stress," "high stress," "very high stress," and "chronic stress" responses were categorized as "high stress."

\section{Anthropometric measures}

Height was measured to the nearest centimeter using a portable stadiometer (Seca, Chino, CA). The weight of each driver was recorded in kilograms to the nearest tenth using an Elite XXL scale. BMI $\left(\mathrm{kg} / \mathrm{m}^{2}\right)$ was calculated and rounded to the nearest tenth. Waist circumference (WC) was assessed using a Gulick II tape measure with tension indicator and values recorded to the nearest tenth of a centimeter. Each measure was taken two times and averaged.

\section{Body mass index and waist circumference}

BMI was categorized as follows: $\leq 24.99 \mathrm{~kg} / \mathrm{m}^{2}$, "healthy"; 25-29.99 kg/m², "overweight"; 30-39.99 kg/m², "obese"; and $\geq 40 \mathrm{~kg} / \mathrm{m}^{2}$, "extreme obese." Waist circumference measures were categorized as follows: $\leq 102 \mathrm{~cm}$, "lower health risks," and > $102 \mathrm{~cm}$, "increased health risks." From these two variables, a composite variable was created to assess for CMD risk based on guidelines from the National Heart, Lung, and Blood Institute (NHLBI) ${ }^{15}$ and categorized as follows: "healthy/low risk," "increased risk," "high risk," "very high risk," and "extremely high risk." Table 1 depicts the NHLBI's classification system.

\section{Potential confounders}

Individual-level factors that could affect the relationship between work hours, schedules, and job stress and CMD risk were treated as potential confounders. ${ }^{13}$ Specific confounding measures for this study included driver age and years of experience in the profession. Other studies have shown younger LHTD to be particularly susceptible to health complications associated with work organization. ${ }^{23}$ Conversely, chronic stress could affect the body physiologically over time and with years of driving experience. For analysis, driver age was categorized as follows: "45 years old or younger" and " 46 years old or older." Years of driving experience was categorized as follows: "10 or fewer years" and "more than 10 years."

\section{Statistical analysis}

Descriptive statistics were used to assess sociodemographic characteristics, anthropometric measures, and work organization features. Logistic regression was used to identify significant predictors of CMD risk, our dependent variable, according to NHBLI standards ${ }^{15}$ 
Table 1. Disease risk* relative to normal weight and waist circumference.

\begin{tabular}{lccc}
\hline & BMI $\left(\mathrm{kg} / \mathrm{m}^{2}\right)$ & Obesity class & Men $<102 \mathrm{~cm}$ \\
\hline Underweight & $<18.5$ & & - \\
Normal & $18.5-24.99$ & & - \\
Overweight & $25.00-29.99$ & & - \\
Obesity & $30.0-34.99$ & Increased & High \\
& $35.0-39.99$ & Hery high & Very high \\
Extreme obesity & $40.0^{+}$ & Very high & Extremely high \\
\hline
\end{tabular}

Note. ${ }^{*}$ Disease risk for type 2 diabetes, hypertension, and CVD.

${ }^{+}$Increased waist circumference also can be a marker for increased risk, even in person of normal weight.

Source: National Heart, Lung, and Blood Institute; National Institutes of Health; U.S. Department of Health and Human Services. Retrieved from http://www.nhlbi. nih.gov/health/educational/lose_wt/BMI/bmi_dis.htm. ${ }^{15}$

(Table 1) and to determine odds ratios. The first logistic regression model included all work organization (work hours, schedules, job stress) and potential confounder variables (driver age, years of experience) as independent predictor variables to assess the fit of the model. The first model was not statistically significant $(p=.44)$; therefore, a second model was constructed to attain statistical significance. This second model was formed by using backward stepwise regression techniques and assessing which independent variables had the most effect on the models and which should be removed. Variables with a $p$ value of greater than .40 from the first model were eliminated from the second model. Eliminated independent variables included experiences with rotating work schedules, delivery scheduling, repetitive work, learning new things, supervisor support, and years of experience. Therefore, the independent variables included in the final logistic regression model included work hours, work pace, experiences with time pressures, coworker support, perceived overall job stress, and driver age. All statistical analyses were conducted using SPSS 23.0. ${ }^{24}$

\section{Results}

\section{Trucker profile, anthropometric measures, and work} organization characteristics

Approximately 360 potential participants were approached at the truck stop, giving us an estimated $72 \%$ response rate. Of those participating, the mean age was 46.63 years and the mean years of driving experience was 14.97. The mean BMI was $33.40 \mathrm{~kg} / \mathrm{m}^{2}$, with $64.3 \%$ being obese and $18.5 \%$ being morbidly or extremely obese. The mean waist circumference was $114.77 \mathrm{~cm}$, with $78.5 \%$ being abdominally obese. When combining waist circumference measures with BMI measures, $80 \%$ of the drivers were at "high risk," "very high risk," or "extremely high risk" of CMD. Participants indicated strenuous work schedules and working hours: $70.4 \%$ averaged working more than 11 hours daily; $82.7 \%$ worked irregular daily schedules; and
$35.8 \%$ considered their delivery schedules to be unrealistic. Similarly, participants indicated high levels of job stress: $46.5 \%$ reported a fast work pace; $51.2 \%$ reported increased time pressures; $81.9 \%$ reported high levels of repetitive work; $59.6 \%$ reported having to frequently learn new things; $64.2 \%$ reported low coworker support; and $27.3 \%$ reported low supervisor support. Surprisingly, only $22.4 \%$ considered their job highly stressful. Tables 2, 3, and 4 provide sociodemographic characteristics, anthropometric measures, and experiences with work organization features.

\section{Association between work organization and cardiometabolic disease risk}

The independent variables included in the second and final logistic regression model using the aforementioned backward stepwise techniques $(X=35.87, p=.05)$

Table 2. Profile of truckers $(N=260)$.

\begin{tabular}{|c|c|c|c|c|}
\hline Characteristic & $n$ & $\%$ & Mean & $S D$ \\
\hline Age & & & 46.63 & 10.53 \\
\hline 45 and younger & 109 & 41.9 & & \\
\hline 46 and older & 151 & 58.1 & & \\
\hline Driving experience & & & 14.97 & 11.53 \\
\hline 10 or fewer years & 97 & 37.3 & & \\
\hline More than 10 years & 163 & 62.7 & & \\
\hline \multicolumn{5}{|l|}{ Race/ethnicity } \\
\hline White/Caucasian & 149 & 57.3 & & \\
\hline Black/African American & 84 & 32.3 & & \\
\hline Hispanic & 22 & 8.5 & & \\
\hline Other & 5 & 1.9 & & \\
\hline \multicolumn{5}{|l|}{ Education } \\
\hline High school or less & 144 & 55.4 & & \\
\hline Some college & 79 & 30.4 & & \\
\hline College degree & 37 & 14.2 & & \\
\hline \multicolumn{5}{|l|}{ Compensation } \\
\hline By the mile & 183 & 70.4 & & \\
\hline By the load & 34 & 13.1 & & \\
\hline$\%$ of revenue & 39 & 15.0 & & \\
\hline Other & 4 & 1.5 & & \\
\hline \multicolumn{5}{|l|}{ Health insurance } \\
\hline None & 87 & 33.5 & & \\
\hline Insured & 173 & 66.5 & & \\
\hline \multicolumn{5}{|l|}{ Union membership } \\
\hline No & 251 & 96.5 & & \\
\hline Yes & 9 & 3.5 & & \\
\hline
\end{tabular}


Table 3. Anthropometric measures and CMD risk $(N=260)$.

\begin{tabular}{lrrrr}
\hline Measure & \multicolumn{1}{c}{$n$} & $\%$ & Mean & SD \\
\hline BMI & & & 33.40 & 7.22 \\
$\quad$ Healthy/normal (24.99) & 27 & 10.4 & & \\
$\quad$ Overweight (25-29.99) & 66 & 25.3 & & \\
$\quad$ Obese (30-39.99) & 119 & 45.8 & & \\
$\quad$ Extreme obese ( 40$)$ & 48 & 18.5 & & \\
Waist circumference & & & 114.77 & 16.56 \\
$\quad$ (02 cm or less & 56 & 21.5 & & \\
$\quad$ Greater than 102 cm & 204 & 78.5 & & \\
CMD risk & & & & \\
Low risk & 27 & 10.4 & & \\
Increased risk & 25 & 9.6 & & \\
$\quad$ High risk & 49 & 18.8 & & \\
$\quad$ Very high risk & 111 & 42.7 & & \\
$\quad$ Extremely high risk & 48 & 18.5 & & \\
\hline
\end{tabular}

Note. $\mathrm{CMD}=$ cardiometabolic disease; $\mathrm{BMI}=$ body mass index.

(Nagelkerke $R^{2}=0.14$ ) were working more than 11 hours per day $(X=9.43, p=.05)$, having a faster work pace $(X=6.57, p=.16)$, having a higher level of time pressure $(X=3.05, p=.55)$, having low coworker support $(X=6.28, p=.18)$, having higher perceived stress $(X=4.97, p=.29)$, and being 45 years of age or younger $(X=10.85, p=.03)$. The statistically significant independent predictors to the second model were working more than 11 hours per day $(p=.05)$ and being 45 or younger $(p=.03)$.

When examining odds ratios, and first using "low/ risk/healthy" as the reference category, we found that working more than 11 hours per day resulted in a $252 \%$

Table 4. Work organization characteristics $(N=260)$.

\begin{tabular}{lrl}
\hline Characteristic & $n$ & $\%$ \\
\hline Daily work hours & & \\
$\quad 11$ or less & 77 & 29.6 \\
$\quad$ More than 11 & 183 & 70.4 \\
Daily work schedule & 45 & 17.3 \\
$\quad$ Same & 215 & 82.7 \\
$\quad$ Different & & \\
Delivery schedule & 93 & 35.8 \\
$\quad$ Unrealistic & 167 & 64.2 \\
$\quad$ Realistic & & \\
Work pace & 139 & 53.5 \\
$\quad$ Slower pace & 121 & 46.5 \\
$\quad$ Faster pace & & 48.8 \\
Time pressures & 127 & 51.2 \\
$\quad$ Lower frequency & 133 & \\
$\quad$ Increased frequency & & 18.1 \\
Repetitive work & 47.9 \\
$\quad$ Lower frequency & & \\
$\quad$ Increased frequency & 213 & 40.4 \\
Learn new things & & 59.6 \\
$\quad$ Lower frequency & & \\
Increased frequency & 105 & 64.2 \\
Coworker support & 155 & 35.8 \\
$\quad$ Lower support & & \\
$\quad$ Increased support & 167 & 27.3 \\
Supervisor support & 93 & 72.7 \\
$\quad$ Lower support & & \\
$\quad$ Increased support & 71.6 \\
Perceived stress & 189 & \\
$\quad$ Lower & & \\
$\quad$ Higher & & \\
\hline
\end{tabular}

increase in odds of having an extremely high risk for CMD; being 45 years old or younger resulted in a $341 \%$ increase in odds of having an extremely high risk for CMD. There were no other positive or negative associations across the groups, outside of the "extremely high risk" group. Drawing on these findings, we compared the "extremely high risk" category against the "increased risk," "high risk," and "very high risk" categories to assess whether the trend in increased odds continued. When using "increased risk" as the reference category, there were no positive or negative associations with working more than 11 hours and being 45 or younger. With "high risk" as the reference category, there was a $190 \%$ increase in the odds of "extremely high risk" for CMD among those drivers 45 years old and younger. With "very high risk" as the reference category, those working more than 11 hours per day had a $249 \%$ increase in odds of "extremely high risk" of CMD, and being 45 or younger had a $153 \%$ increase in odds of "extremely high risk" of CMD. Odds ratios can be found in Table 5.

\section{Comment}

This sample of US LHTD $(N=260)$ had an average BMI of 33.40 , with $64.3 \%$ being obese; the average

Table 5. Associations between work organization and CMD $(N=260)$. $^{*}$

\begin{tabular}{|c|c|c|c|}
\hline Extremely high risk for CMD & Odds ratio & $95 \% \mathrm{Cl}$ & $p$ value \\
\hline \multicolumn{4}{|l|}{ Reference: healthy/low risk } \\
\hline Working more than 11 hours & 3.52 & {$[1.10,11.20]$} & .03 \\
\hline Faster work pace & 1.18 & {$[0.38,3.61]$} & .78 \\
\hline High levels of time pressure & 0.83 & {$[0.27,2.54]$} & .74 \\
\hline Low coworker support & 1.59 & {$[0.58,4.35]$} & .37 \\
\hline Higher perceived job stress level & 2.24 & {$[0.64,7.77]$} & .21 \\
\hline 45 and younger & 4.41 & {$[1.53,12.67]$} & .01 \\
\hline \multicolumn{4}{|l|}{ Reference: increased risk } \\
\hline Working more than 11 hours & 2.16 & {$[0.62,7.47]$} & .22 \\
\hline Faster work pace & 0.28 & {$[0.09,0.86]$} & .03 \\
\hline High levels of time pressure & 1.67 & {$[0.55,5.10]$} & .37 \\
\hline Low coworker support & 0.45 & {$[0.15,1.37]$} & .16 \\
\hline Higher perceived job stress level & 0.74 & {$[0.19,2.98]$} & .68 \\
\hline 45 and younger & 2.61 & {$[0.92,7.42]$} & .07 \\
\hline \multicolumn{4}{|l|}{ Reference: high risk } \\
\hline Working more than 11 hours & 2.63 & {$[0.95,7.27]$} & .06 \\
\hline Faster work pace & 0.89 & {$[0.36,2.20]$} & .80 \\
\hline High levels of time pressure & 1.26 & {$[0.50,3.15]$} & .62 \\
\hline Low coworker support & 0.71 & {$[0.30,1.67]$} & .43 \\
\hline Higher perceived job stress level & 2.33 & {$[0.83,6.58]$} & .11 \\
\hline 45 and younger & 2.90 & {$[1.24,6.75]$} & .01 \\
\hline \multicolumn{4}{|l|}{ Reference: very high risk } \\
\hline Working more than 11 hours & 3.49 & {$[1.44,8.48]$} & .01 \\
\hline Faster work pace & 0.72 & {$[0.33,1.55]$} & .40 \\
\hline High levels of time pressure & 1.66 & {$[0.76,3.60]$} & .20 \\
\hline Low coworker support & 0.62 & {$[0.30,1.29]$} & .20 \\
\hline Higher perceived job stress level & 1.47 & {$[0.58,3.76]$} & .42 \\
\hline 45 and younger & 2.53 & {$[1.23,5.20]$} & .01 \\
\hline
\end{tabular}

Note. $\mathrm{CMD}=$ cardiometabolic disease; $\mathrm{Cl}=$ confidence interval.

${ }^{*}$ Only includes independent predictor variables after the backward stepwise regression technique. This takes into account and adjusts for the potential confounders of age and years of driving experience. 
waist circumference was nearly $115 \mathrm{~cm}$, and $78.5 \%$ were abdominally obese. Both obesity measures were far greater than those for a matched sample of the US population during that same period $(\mathrm{BMI}=27.6$ $\left.\mathrm{kg} / \mathrm{m}^{2} ; \mathrm{WC}=91.8 \mathrm{~cm}\right) .{ }^{25,26}$ For BMI specifically, the BMI of this LHTD sample was much higher than that for all male US workers $\left(B M I=28.0 \mathrm{~kg} / \mathrm{m}^{2}\right)$, the transportation and warehousing industry in general $\left(\mathrm{BMI}=28.5 \mathrm{~kg} / \mathrm{m}^{2}\right)$, and other industries with the highest estimated BMIs, including public administration $\left(\mathrm{BMI}=29.0 \mathrm{~kg} / \mathrm{m}^{2}\right)$, mining $(\mathrm{BMI}=28.7 \mathrm{~kg} /$ $\mathrm{m}^{2}$ ), and utilities $\left(\mathrm{BMI}=28.6 \mathrm{~kg} / \mathrm{m}^{2}\right){ }^{27}$ Further, the mean BMI of this LHTD sample is identical to that of the National Survey of US Long-Haul Truck Driver Health and Injury, which included 1,265 LHTDs. ${ }^{14}$ When combining BMI and waist circumference measures, $80 \%$ of the sample had a "high risk," "very high risk," or "extremely high risk" of developing CMD. This is not surprising, considering that most people who are generally obese will also be abdominally obese, which suggests that BMI may remain an effective measure for CMD risk. ${ }^{28}$ For CMD risk, specifically for an "extremely high risk," longer work hours were statistically significant in terms of raising the odds ratios. These findings concur with the review by Soloveiva and colleagues, which concluded longer work hours are the most critical aspect of work organization related to weight status. ${ }^{13}$

It appears that long work hours could negatively influence US LHTD obesity-associated CMD risk through behavioral and biochemical mechanisms. ${ }^{1}$ Behaviorally, longer hours of work could allow for less time to exercise and obtain physical activity. ${ }^{29}$ Biochemically, chronic stress from repeated long-hour days can alter weight status through hormone imbalances, namely, leptin. ${ }^{30}$ Long work hours have also been associated with sleep deprivation, which can affect the body physiologically, specifically cortisol levels, and create abnormal stress responses. ${ }^{2}$ Prolonged sleep deprivation and sleep disorders, induced by longer working hours and induced or exacerbated by unhealthy weight status, detrimentally affect the body's endocrine system and metabolic rate. ${ }^{3}$ Previous studies linked longer work hours and obesity as mediated by shorter sleep duration. ${ }^{31}$ Somewhat surprisingly, the odds for CMD risk were significantly higher for individuals in the younger age groups. Other studies have similarly found that younger men are more likely than older workers to gain weight with increased work hours. $^{13}$

Surprisingly, scheduling and job stress variables in this study were not significantly associated with CMD risk. Regarding scheduling variables, the aforementioned National Survey of US Long-Haul Truck Driver Health and Injury similarly featured questions that gauged perceptions of LHTD as to whether their work schedules were realistic. In contrast with our sample of LHTD, $36 \%$ of whom indicated their delivery schedules to be unrealistic, $74 \%$ of the national sample indicated that they often or sometimes received an unrealistically tight delivery schedule. ${ }^{32}$ However, the national sample featured a questionnaire that explored scheduling pressures using different questions; thus, the lack of significant associations found in the current study may be due to how these factors were assessed. Regarding job stress variables, higher job demands, combined with a lack of authority, have been previously associated with higher risks for weight gain among US adults. ${ }^{33}$ Likewise, findings from the Whitehall II study showed that chronic work stress predicted both general and abdominal obesity. ${ }^{34}$ However, the measures of job stress in the current study were not validated, and the aforementioned studies that found connections between job stress and CMD risk used alternate measures. Potential explanations for our contrary findings could also be the unique nature of US long-haul truck driver work, which mitigates the role of supervisors because of the limited face-to-face contact; the unique cultural milieu of the long-haul truck driving profession in the United States, which emphasizes rugged individuality and self-reliance; or the self-report research design employed to examine the job stress variables.

Effective and sustainable workplace intervention efforts to reduce CMD risk among US LHTDs are critically needed. Heightened CMD risk among LHTDs burdens the US trucking industry through excessive health care costs and reduced labor productivity. ${ }^{35}$ Given the importance of the trucking industry to the broader US economy, long-haul truck driver health has negative effects for multiple stakeholders, such as insurance companies, health care systems, manufacturing and warehousing firms, and truck stop companies. ${ }^{7}$ Finally, CMD risk has implications for public safety, as factors such as hypertension, obesity, diabetes, and CVD impair key safe driving abilities. ${ }^{36,37}$

Insights gained from this study align with burgeoning trends among workplace wellness practitioners and scholars; in particular, increasing emphasis on accommodating work organization influences as part of workplace interventions and increasing recognition of the need for integrated and comprehensive interventions. ${ }^{7,14,38,39}$ Workplace interventions in the trucking industry have focused on individual-level behavioral change, generally neglecting upstream influences such as work organization. ${ }^{39}$ For health and wellness interventions for truck drivers to reduce CMD risk, addressing work hours appears to be a key work organization leverage point. ${ }^{7}$ Integrated and comprehensive interventions 
should address organizational practices and public policies, particularly those related to the HOS regulations, which influence work hours of US LHTDs. Such interventions could benefit from a complex systems science perspective framework. ${ }^{40}$ Because of the unique characteristics of US long-haul trucking, integrated and comprehensive interventions addressing work organization factors would require multidisciplinary collaboration from multiple and diverse stakeholders to achieve sustainable population-level effects on CMD risk. ${ }^{7}$

The study has several limitations. As a result of the cross-sectional research design, causal connections cannot be claimed due to any established associations. A longitudinal design is needed to elucidate relationships between work organization and CMD risk. For example, it is possible that CMD outcomes may be masked in our data by medical examination requirements imposed on LHTDs, as federal policy stipulates that drivers must undergo a medical screening process at least biennially. ${ }^{41}$ In turn, those that meet the requirements are frequently on medication to control for CMD outcomes such as hypertension, cholesterol, and diabetes. Thus, a survivor effect may be present in our data, as LHTDs become medically disqualified due to the manifestation of CMD disease states or other related causes associated with heightened CMD risk. Furthermore, due to the use of a nonvalidated instrument that relied on self-report measures and potential driver selection and retention bias, the findings may be misleading. In addition, this instrument did not measure food intake or dietary patterns, which are influential in obesity and CMD risk. However, because this study did not focus on health behaviors, the effects of this limitation are mitigated. The LHTD sample was also modest in size and was a convenience sample, as data were collected at one truck stop in North Carolina. As such, and although the nature of the LHTD profession mitigates potential place-based effects in our sampling procedures, the results from this study may not be generalizable for all US LHTDs. In general, there is a dearth of data pertaining to US LHTDs; thus, there is a need for myriad studies investigating the unique influences that induce elevated CMD risk among this population. Immediate needs for future studies of US LHTDs include larger and more representative samples, incorporating health behavior (physical activity, diet, sleep, etc.), biological (insulin, cholesterol, lipids, etc.), and longitudinal data.

\section{Conclusions}

Longer work hours, endemic to US LHTD work organization, are associated with increased odds of both general and abdominal obesity and increased CMD risk. While most interventions targeting CMD risk among US LHTDs have focused on individual-level behavioral changes, these findings point to work organization, and in particular long working hours, as a focal target for integrated and comprehensive interventions to reduce US LHTD CMD risk.

\section{Acknowledgments}

We thank Mr. Tom Liutkus, Vice President of Marketing and Public Relations for Travel Centers of America (TA), and Mr. Jerald Brisson, General Manager of the Whitsett, NC TA truck stop, and his staff for their instrumental support for our project and data collection efforts. We also thank the long-haul truck drivers who participated in this study and extend our thanks to our graduate students Kiki Hatzudis (Public Health Education) and Doug Oberlin (Kinesiology) for their invaluable assistance in various phases of data collection.

\section{Funding}

This article is part of a commercial driver sleep study conducted with research funds awarded to Yorghos Apostolopoulos by the University of North Carolina-Greensboro's (UNCG) Office of Research and Economic Development. Additional funds were provided by UNCG's School of Health and Human Sciences, Bryan School of Business and Economics, Department of Public Health Education, and Department of Kinesiology. The authors report no conflicts of interest.

\section{References}

1. Landsbergis PA, Grzywacz JG, LaMontagne AD. Work organization, job insecurity, and occupational health disparities. Am J Ind Med. 2014;57:495-515.

2. Johnson JV, Lipscomb J. Long working hours, occupational health and the changing nature of work organization. Am J Ind Med. 2006;49:921-929.

3. Caruso CC. Negative impacts of shiftwork and long work hours. Rehabil Nurs. 2014;39:16-25.

4. Alterman T, Luckhaupt SE, Dahlhamer JM, Ward BW, Calvert GM. Prevalence rates of work organization characteristics among workers in the US: data from the 2010 National Health Interview Survey. Am J Ind Med. 2013;56:647-659.

5. Häusser JA, Mojzisch A, Niesel M, Schulz-Hardt S. Ten years on: a review of recent research on the Job DemandControl (-Support) model and psychological well-being. Work \& Stress. 2010;24:1-35.

6. Belkic KL, Landsbergis PA, Schnall PL, Baker D. Is job strain a major source of cardiovascular disease risk? Scand J Work Environ Health. 2004;30:85-128.

7. Apostolopoulos Y, Lemke M, Sönmez S. Risks endemic to long-haul trucking in North America: strategies to protect and promote driver well-being. New Solut. 2014;24:57-81. 
8. Belman DL, Monaco KA. The effects of deregulation, deunionization, technology, and human capital on the work and work lives of truck drivers. Ind Labor Relations Rev. 2001;54:502-524.

9. Hege A, Perko M, Johnson A, Yu CH, Sönmez S, Apostolopoulos Y. Surveying the impact of work hours and schedules on commercial motor vehicle driver sleep. Safety and Health at Work. 2015;6:104-113.

10. Apostolopoulos Y, Sönmez S, Shattell M. Worksiteinduced morbidities of truck drivers in the United States. AAOHN J. 2010;58:285-296.

11. US Bureau of Labor Statistics. Causes of fatal occupational injuries summary, 2014. http://www.bls.gov/news.release/ cfoi.nr0.htm. Accessed June 18, 2016.

12. Apostolopoulos Y, Lemke M, Sönmez S, Hege A. The obesogenic environment of commerical trucking: a worksite environmental audit and implications for systems-based interventions. Am J Health Educ. 2016;47:85-93.

13. Solovieva S, Virtanen M, Viikari-Juntura E. Psychosocial factors at work, long work hours, and obesity: a systematic review. Scand J Work Environ Health. 2013;39:241-258.

14. Sieber WK, Robinson CF, Birdsey J, et al. Obesity and other risk factors: the national survey of US long-haul truck driver health and injury. Am J Ind Med. 2014;57:615-626.

15. National Heart, Lung, and Blood Institute. Classification of overweight and obesity by bmi, waist circumference, and associated disease risks. https://www.nhlbi.nih.gov/ health/educational/lose_wt/BMI/bmi_dis.htm. Accessed September 15, 2015.

16. Tremblay MS, Gaudet D, Brisson D. Metabolic syndrome and oral markers of cardiometabolic risk. J Can Dent Assoc. 2011;77:b125.

17. Esser N, Legrand-Poels S, Piette J, Scheen AJ, Paquot N. Inflammation as a link between obesity, metabolic syndrome and type 2 diabetes. Diabetes Res Clin Pract. 2014;105:141-150.

18. Schulte PA, Wagner GR, Ostry A, et al. Work, obesity, and occupational safety and health. Am J Public Health. 2007;97:428-436.

19. Apostolopoulos Y, Sönmez S, Shattell M, Belzer MH. Environmental determinants of obesity-associated morbidity risks for truckers. Int $J$ Workplace Health Manag. 2012;5:120-138.

20. Netzer N, Stoohs R, Clark K, Strohl K. Using the Berlin Questionnaire to identify patients at risk for the sleep apnea syndrome. Ann Intern Med. 1999;31:2087-2095.

21. Philip P, Akerstedt T. Transport and industrial safety, how are they affected by sleepiness and sleep restriction? Sleep Med Rev. 2006;10:347-356.

22. Federal Motor Carrier Safety Administration. Summary of hours-of-service regulations. http://www.fmcsa.dot.gov/ rules-regulations/topics/hos/index.htm. Accessed April 1, 2016.

23. Lemke MK, Hege A, Perko M, Sönmez S, Apostolopoulos Y. Work patterns, sleeping hours, and excess weight in commercial drivers. Occup Med. 2015;65:725-731.

24. IBM Corp. SPSS statistics for Windows, version 23.0. Armonk, NY: IBM Corp; 2015.
25. Apostolopoulos Y, Lemke MK, Hege A, et al. Work and chronic disease: comparison of cardiometabolic risk markers between truck drivers and the general US population. J Occup Environ Med. In press.

26. National Center for Health Statistics. National Health and Nutrition Examination Survey. http://www.cdc.gov/nchs/ nhanes/. Accessed April 7, 2016.

27. Luckhaupt SE, Cohen MA, Li J, Calvert GM. Prevalence of obesity among US workers and associations with occupational factors. Am J Prev Med. 2014;46:237-248.

28. Abbasi F, Blasey C, Reaven GM. Cardiometabolic risk factors and obesity: does it matter whether BMI or waist circumference is the index of obesity? Am J Clin Nutr. 2013;98:637-640.

29. Turner LM, PHCNS-BS R. Exercise among commercial truck drivers. Workplace Health \& Safety. 2011;59:429.

30. Ramachandrappa S, Farooqi IS. Genetic approaches to understanding human obesity. J Clin Invest. 2011;121: 2080-2086.

31. Magee CA, Caputi P, Iverson DC. Short sleep mediates the association between long work hours and increased body mass index. J Behav Med. 2011;34:83-91.

32. Chen GX, Sieber WK, Lincoln JE, et al. National survey of US long-haul truck drivers: injury and safety. Accident Analysis \& Prevention. 2015;85:66-72.

33. Block JP, He Y, Zaslavsky AM, Ding L, Ayanian JZ. Psychosocial stress and change in weight among US adults. Am J Epidemiol. 2009;170;181-192.

34. Brunner EJ, Chandola T, Marmot MG. Prospective effect of job strain on general and central obesity in the Whitehall II Study. Am J Epidemiol. 2007;165:828-837.

35. Martin B, Church T, Bonnell R. The impact of overweight and obesity on the direct medical costs of truck drivers. $J$ Occup Environ Med. 2009;51:180-184.

36. Anderson JE, Govada M, Steffen TK, et al. Obesity is associated with the future risk of heavy truck crashes among newly recruited commercial drivers. Accident Analysis \& Prevention. 2012;49:378-384.

37. Mueleners LB, Lee AH. Driving fitness, health profile and issues affecting heavy vehicle drivers: opportunities for accident prevention. New York, NY: Nova Science.

38. Ng MK, Yousuf B, Bigelow PL, Van Eerd D. Effectiveness of health promotion programmes for truck drivers: a systematic review. Health Educ J. 2015;74:270-286.

39. Lemke M, Apostolopoulos Y. Health and wellness programs for commercial motor-vehicle drivers: organizational assessment and new research directions. Workplace Health \& Safety. 2015;63:71-80.

40. Lemke MK, Apostolopoulos Y. Policy, work organization and sleep health and safety of commercial drivers: introducing a complex systems paradigm. J Ergonomics. 2016;6:152-156.

41. Federal Motor Carrier Safety Administration. DOT medical exam and commercial motor vehicle certification. https://www.fmcsa.dot.gov/medical/driver-medi cal-requirements/dot-medical-exam-and-commercialmotor-vehicle-certification. Accessed November 11, 2015. 